\title{
UTILIZAÇÃO DE FERRAMENTAS DIGITAIS DE SIMULAÇÃO DE ILUMINAÇÃO NATURAL NO PROCESSO DE PROJETO BIOCLIMÁTICO
}

\author{
Carolina Eloisa Jochims, mestranda (UFSC/ULBRA) \\ Orientador: Anderson Claro, Dr. (UFSC) \\ Coorientadora: Lisiane Ilha Librelotto, Dra (UFSC)
}

Aos projetos arquitetônicos acrescentaram-se novos desafios, advindos das mudanças climáticas globais, da diminuição dos recursos naturais e das restrições em termos de energia. Nesse contexto, os preceitos da arquitetura bioclimática representam necessidade e esperança em termos de sustentabilidade ambiental, dado o impacto provocado pelas edificações na degradação do planeta. O correto aproveitamento de calor, vento e luz disponíveis em cada local pode promover não apenas a economia de recursos naturais e econômicos, mas a meIhoria nas condições de desempenho de tarefas, de conforto e de saúde dos ocupantes das construções.

A luz natural, que atua diretamente nos sistemas fisiológico e psicológico dos seres humanos, deve ser garantida de forma suficiente nos ambientes, ao longo do dia, através dos projetos. Cresce assim, a importância da comprovação das intenções de projeto nas futuras construções, bem como do atendimento às normas em vigor.

Esse resumo apresenta os resultados obtidos em uma dissertação de mestrado do Programa de Pós-Graduação em Arquitetura e Urbanismo da Universidade Federal de Santa Catarina, que teve como objetivo a análise da utilização de ferramentas digitais de simulação de iluminação natural nas diferentes fases de um processo de projeto bioclimático.

A pesquisa dividiu-se em quatro etapas: revisão bibliográfica, pesquisa-ação, análise de resultados e proposição. Na etapa de pesquisa-ação, utilizou-se num primeiro momento um projeto piloto, para fins de compreensão e testes. Executado a partir dos dados climáticos da zona bioclimática 8 para a cidade do Rio de Janeiro, de acordo com as recomendações da NBR 15220-3:2003 Zoneamento bioclimático brasileiro, o projeto teve como ênfase inicial a variável térmica. Num segundo momento foram analisados através da ferramenta digital Apolux versão Beta 3 (CLARO, 2012) alguns dos itens de iluminação natural inseridos no projeto inicial com base na intuição e na experiência profissional da autora. Para as simulações foi estabelecido como parâmetro o atendimento às normas ABNT ISO/CIE 8995-1:2013: Iluminação de ambientes de trabalho - Parte 1: Interior, devido à possibilidade de utilização do espaço analisado como home office, e à NBR 15575/2013- Desempenho de edificações habitacionais. Para análise do resultado de intenção de projeto quanto a um efeito de iluminação desejado, foram utilizadas imagens geradas pela ferramenta de simulação Apolux.

Como contribuição do estudo, foi proposto um possível roteiro de utilização de ferramentas digitais de simulação de iluminação natural em um processo de projeto bioclimático.

Os resultados das análises demonstraram o atendimento aos parâmetros normativos estabelecidos, tanto em relação ao fator de luz diurna (FLD) mínimo de 6\%, quanto à iluminância mínima de 500 lux. Já a intenção de projeto em relação ao efeito de luz se revelou frustrada, servindo a ferramenta para indicação de solução. A conclusão do trabalho é de que a simulação de iluminação natural, em integração permanente ao processo de projeto, desde a sua fase inicial e em suas diferentes etapas, provê dados importantes como auxílio a projetistas, para fins de análise e melhorias do projeto e da futura edificação.

\section{REFERÊNCIAS}

APOLUX Beta versão 4. Programa para cálculo de iluminação natural. 2016. Disponível em: <foton.arq. ufsc.br>. Acesso em: 19/08/2016.

Associação Brasileira de Normas Técnicas ABNT ISO/ CIE 8995-1:2013: Iluminação de ambientes de trabalho - Parte 1: Interior. Rio de Janeiro: ABNT, 2013.

Associação Brasileira de Normas Técnicas (ABNT) NBR 15575-1:2013 - Edificações Habitacionais Desempenho - PARTE 1 - Requisitos gerais. Rio de Janeiro: ABNT, 2013. 